\title{
Assessment of Drug Adherence Level According to the Patients' Opinion: Results of Research in Lviv of Ukraine
}

\author{
Tetiana Ryvak*, Khrystyna Makukh, Andriy Zimenkovsky \\ Department of Clinical pharmacy, Pharmacotherapy and Medical Standardization, Danylo Halytsky Lviv National Medical University, Lviv, Ukraine.
}

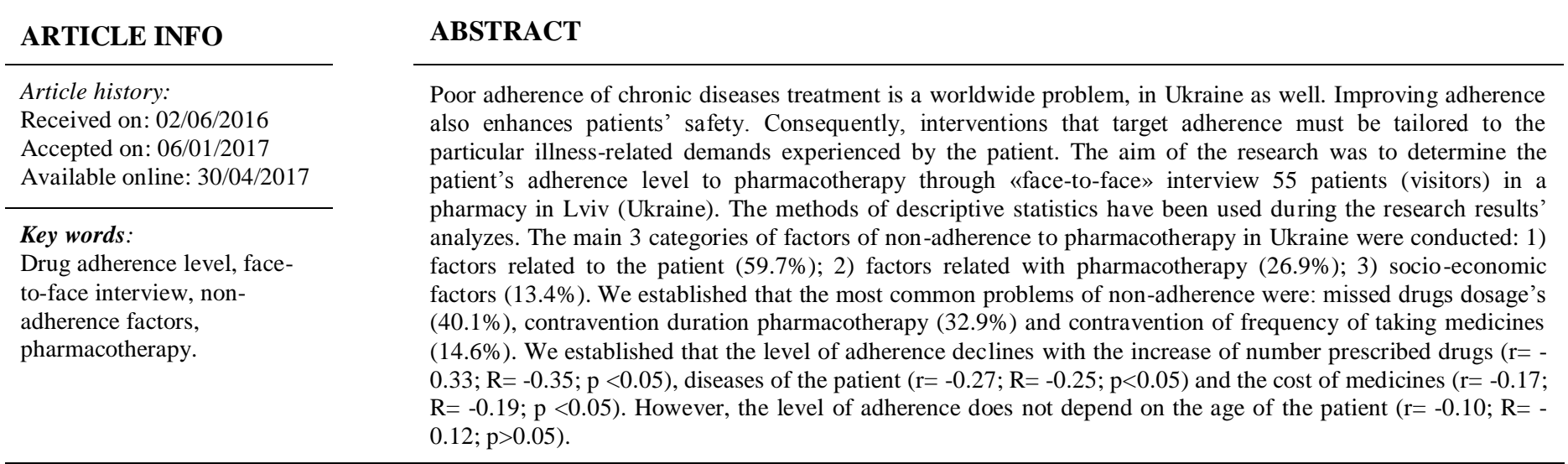

\section{INTRODUCTION}

In the modern health care system the worldwide problem (of patient's compliance degree towards prescribed pharmacotherapy) is increasing. In particular, foreign scientists use the term adherence (Delamater, 2006; Hema and Padmalatha, 2014; Koncz, 2010; Sabate, 2003). According to the WHO (2001) adherence is «the extent to which the patient follows medical instructions» (Sabate, 2003). Adherence - the extent to which a patient's medication intake behavior corresponds with their health care provider agreed recommendations (Wasilewski et al., 2014; Van den Bemt et al., 2012). Adherence to long-term chronic illnesses therapy in developed countries

\section{* Corresponding Author}

Tetiana Ryvak, Pharmaceutical Faculty, Department of Clinical pharmacy, Pharmacotherapy and Medical Standardization, Danylo Halytsky Lviv National Medical University, Lviv, 79010, Ukraine. E-mail: tanita05 @ yandex.ua averages $50 \%$. In developing countries, the rates are even lower. It is undeniable that many patients have experienced difficulty in following treatment recommendations (Sabate, 2003). Nonadherence to pharmacotherapy has been reported to range from $13 \%$ to $93 \%$, with an average rate of $40 \%$. The problem encompasses all ages and ethnic groups. It has been estimated that $43 \%$ of the general population, $55 \%$ of the elderly, and $54 \%$ of children and teenagers are non-adherent. Rates of non-adherence vary with different disease states.

For example, the non-adherence rate for hypertension is reported to be $40 \%$, while that for arthritis has been found to range between $55 \%$ and $70 \%$. Non-adherence rates are especially high among patients with chronic diseases. These patients, who typically require long-term, if not lifelong, medications to control symptoms and prevent complications, often must make significant behavioral changes to adhere with pharmacotherapy. Such changes can be difficult to integrate into everyday life (Nichols and Poirier, 2000). 
Moreover, the annual costs of non-adherence for all conditions in the US have been estimated to be $\$ 100$ billion (Osterberg and Blaschke, 2005; Zwikker et al., 2014). Nonadherence to needed medicines has many forms. While the most common is simply forgetting to take a prescribed medicine, almost $1 / 3$ of patients stop taking their medicine earlier than instructed. Overall, nearly $75 \%$ of adults are non-adherent in one or more ways, such as not filling a new prescription or taking less than the dose recommended by the physician (PhRMA, 2011). In multivariate analyses, medication class was the strongest predictor of adherence, and non-adherence was common for newly prescribed medications treating chronic conditions such as hypertension (28.4\%), hyperlipidemia (28.2\%), and diabetes (31.4\%). (Fischer et al., 2010). A 2nd study reports that new prescriptions for common maintenance medicines to control asthma and treat high cholesterol went unfilled $20 \%$ and $34 \%$ of the time, respectively (PhRMA, 2011).

Results of modern informational search showed that foreign scientists have proposed several methods for determining medicine adherence. In particular, the methodologies of determining adherence provide a number of subjective and objective methods (Koncz, 2010). Subjective single methods include: patient interview method; calculation of tablets after pharmacotherapy (when compared to the remainder of the total number of tablets that had to be taken); electronic database et al. Subjective, multiple periodic updated flexible methods include: patient's diary and retrospective questionnaire. The most objective method is electronic compliance monitoring. Nevertheless, due to its reliability and objectiveness it is considered the gold standard of adherence measurement (Koncz, 2010). One of the methods that are often used abroad for adherence determining in patients with chronic diseases is the answers scale MMAS-8 (2012) (Hema and Padmalatha, 2014; Nagarkar et al., 2013; Wasilewski et al., 2014). In Ukraine, studies to determine patient's adherence held are still not sufficient; however, the relevance of this issue in the national health care system hasn't become less important. Improvement of pharmacotherapy quality is closely linked with adherence because its high level is the key to achieve the most effective treatment results, which defined the objectives, strategy and design of our study.

\section{MATERIALS AND METHODS}

Study design: «face-to-face» 55 patients interviewed visitors of the pharmacy in Lviv (Ukraine) of different age, gender and existing diseases in a specially designed by us standardized questionnaire. The main criterions for including of patients were: several diseases simultaneously and application more than one prescribed drugs (polypharmacy). The questionnaire was composed of socio-demographic characteristics, patient related factors and health care related characteristics. For data processing and analysis, the initial amount of information has been transformed into a tabular electronic format. Demographic description of the respondents, included in the research according to the main parameters is presented in Table 1. Information resource: physician's prescriptions from out patients' medical card; drug instructions for medical use registered in Ukraine (The State drugs list of Ukraine, 2015); the weighted average retail price of drugs (The Average Retail Price of Medicines in Ukraine, 2015). The system analysis, standardization, analytical and comparative, clinical and pharmaceutical, sociological («face-toface» interview) and statistical methods have been applied. The conflict of the interests in the course of the research is absent. The Conclusion of Human Research Ethics Committee of Danylo Halytsky Lviv National Medical University is in minutes No 4, $20^{\text {th }}$ April 2015.

The statistical analysis of the results was carried out in "Statistica" (v8.0 Stat. Soft Inc., USA). The methods of descriptive statistics have been used during the analysis of research results. The standard deviation (SD) of the sample was determined for each of the researched parameters. Normality of quantitative data distribution was checked by means of Shapiro-Wilk test. It was established that the distribution of the sample is different from a normal $(\mathrm{p}<0.05)$. The results were considered authentic at a significance level $p<0.05$. Force and direction of the correlation between the values of studied variables were defined by means of correlation analysis using correlation coefficient (r). Distinction tests between two variables studied were performed with application of Spearman's Rank Correlation Coefficient (R). Besides, regression analysis was conducted. In order to determine form of dependence between two variables a diagram dispersion was used (Scatterplot).

\section{RESULTS}

We established that the largest share among the analyzed clinical diagnoses according to ICD $(\mathrm{n}=90)$ were cardiovascular (35.5\%) and renal disorders (16.7\%) (Table 2).

According to the John Urquhart the eminent early researcher of adherence (Koncz, 2010), patients needing chronic medications are divided into six groups: a) patients who adhere perfectly, taking the right dose at the right time; $b$ ) patients who do not always take their medication at the right time, but they take the right dose; c) patients who occasionally miss a dose and delay their dosing; d) patients who miss several doses and have 3-4 days of drug holidays (drug holiday: a few consecutive days per year with no medication intake); e) patients who have drug holidays approximately each month; f) patients who take little or no prescribed medication (Koncz, 2010). In our study, we used three methods of adherence determining (Table 3 ).

The study was conducted on patients with several different diseases simultaneously (polimorbiding) and with plenty of prescribed drugs (polypharmacy). In particular, one patient in a pharmacotherapy scheme applied some of the medicines at $100 \%$, others - only partially $1 / 2,1 / 3,1 / 4$, or did not apply the drugs at all. Considering features of the study, in our opinion, the most appropriate method of determining adherence was the method based on the above mentioned formulas. 
Table 1: Basic research parameters descriptive statistics.

Respondents' number, $\mathrm{N}$

Characteristics

Value
55
$19(34.5)$
$36(65.5)$
$8-88$
$59.4 \pm 16.7$
$1.7 \pm 0.8$
$2.4 \pm 1.6$
$57.8 \pm 29.3$

F, abs. (\%)

Age, min-max, years

Respondents' average age, years \pm SD

Average number of diseases per 1 patient \pm SD

Average number of medicines per 1 patient \pm SD

Table 2: Distribution of clinical diagnosis of patients according to ICD, included in the study.

\begin{tabular}{|c|c|c|c|}
\hline Disorders & Basic clinical diagnosis & Frequency $(n=90)$ & Percentage \\
\hline \multirow{9}{*}{ orders $(n=32)$} & Hypertension & 13 & \multirow{9}{*}{35.5} \\
\hline & Peripheral arterial embolism & 6 & \\
\hline & Ischemic Heart Diseases (IHD) & 4 & \\
\hline & Atherosclerosis & 4 & \\
\hline & Myocardial infarction in anamnesis & 1 & \\
\hline & Bradycardia & 1 & \\
\hline & TELA & 1 & \\
\hline & Trombophlebitis & 1 & \\
\hline & Lymphostasis & 1 & \\
\hline \multirow{8}{*}{ =15) } & Prostatitis & 4 & \multirow{8}{*}{16.7} \\
\hline & Cystitis & 3 & \\
\hline & Urolithicdeseases & 3 & \\
\hline & Pyelonephritis & 1 & \\
\hline & Urine incontinence & 1 & \\
\hline & Benign prostatic hyperplasia & 1 & \\
\hline & Fybromioma & 1 & \\
\hline & Adenomyosis & 1 & \\
\hline \multirow{5}{*}{$\operatorname{rders}(n=12)$} & Osteoporosis & 3 & \multirow{5}{*}{13.3} \\
\hline & Osteoarthritis & 4 & \\
\hline & Rheumatoid arthritis & 2 & \\
\hline & Gout & 2 & \\
\hline & Osteochondrosis & 1 & \\
\hline \multirow{4}{*}{ orders $(n=10)$} & Hypothyroiditis & 3 & \multirow{4}{*}{-11.1} \\
\hline & Diabetes mellitus & 3 & \\
\hline & Nodular diseases of thyroids gland & 2 & \\
\hline & Thyreotoxicosis & 2 & \\
\hline \multirow{6}{*}{ eases $(n=9)$} & PUD & 3 & \multirow{7}{*}{10.0} \\
\hline & Ulcerative colitis & 1 & \\
\hline & Chronic gallbladder stone disease & 2 & \\
\hline & Hepatitis & 1 & \\
\hline & Chronic pancreatitis & 1 & \\
\hline & Helminthosis & 1 & \\
\hline \multirow{3}{*}{ rs $(n=6)$} & Neurastenia & 3 & \\
\hline & Transitor ischemic attack & 2 & \multirow{2}{*}{-6.7} \\
\hline & Ischemic Stroke attack & 1 & \\
\hline \multirow{5}{*}{$(n=3)$} & Lung cancer & 2 & \multirow{2}{*}{-3.3} \\
\hline & Prostate cancer & 1 & \\
\hline & Demodecosis & 1 & \multirow{3}{*}{3.3} \\
\hline & Eczema & 1 & \\
\hline & Chronic bronchitis & 1 & \\
\hline
\end{tabular}

Bone and joint disorders $(n=12)$

Renal disorders $(n=15)$

Cardiovascular disorders $(\mathrm{n}=32)$

Bone and joint disorders $(n=12)$

Endocrinologic disorders $(\mathrm{n}=10)$

Neurologic disorders $(n=6)$

Oncology disorders $(n=3)$

Others $(n=3)$

Chronic bronchitis

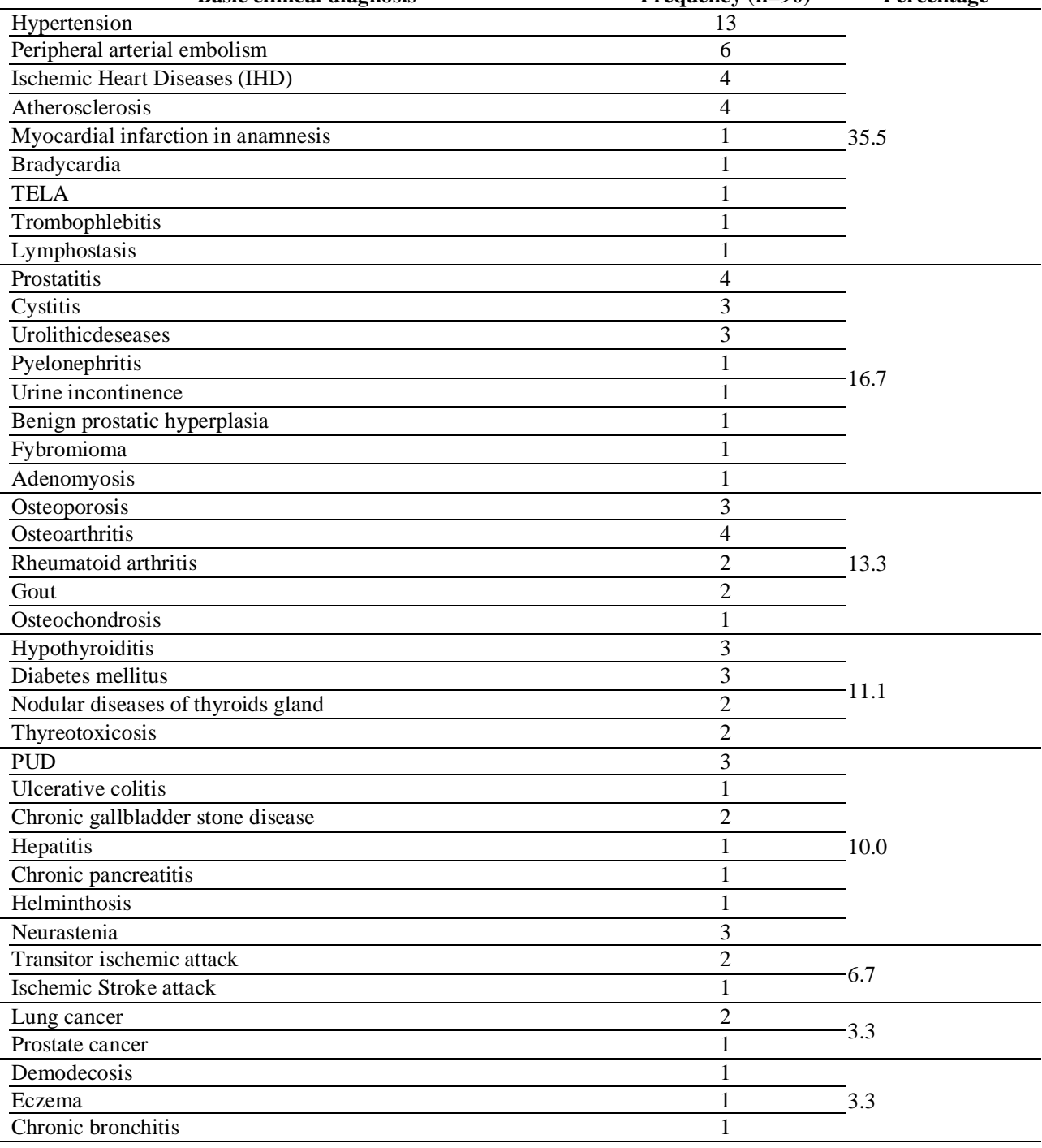

Table 3: Characteristics of certain methods of adherence level calculating.

\begin{tabular}{lcc}
\hline No & Methods & Formula \\
1. & Taking compliance & $\frac{\text { recorded medication events }}{\text { prescribed doses }} \times 100 \%$ \\
\hline 2. & Correct dosing & $\frac{\text { day s when the prescribed doses were correctly taken }}{\text { total therapeutic days }} \times 100 \%$ \\
\hline 3. & Timing compliance & day s when patient has correct interval doses \\
\hline
\end{tabular}


Most frequent reasons of non-adherence were missed drugs dosage by the patients $(65.5 \%)$ and $58.2 \%$ - insufficient duration of pharmacotherapy (Figure 1). We established that only in 2 cases, patients followed all doctor's prescriptions $(100 \%$ adherence).

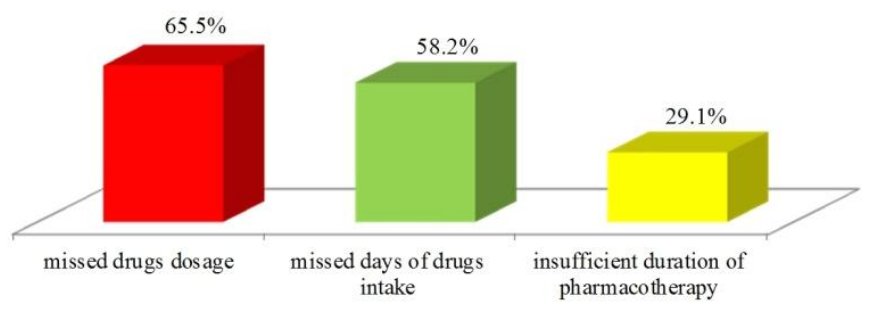

Fig. 1: Reasons for non-adherence of pharmacotherapy in analyzed 55 patients.

Having adopted the scale of adherence level according to Briesacher B.A. (PhRMA, 2011), we proposed own gradation, which foresees 5 categories: 1 - high adherence (100-81\%); 2 sufficient (80-61\%); 3 - average (60-41\%); 4 - low (40-21\%); 5 insufficient (20-0\%) (Table 4).

Table 4: Gradation of adherence level of the patients under the study, according to 5 categories offered.

\begin{tabular}{ccc}
\hline Category & Gradation of adherence level & Percentage \\
\hline $\mathbf{1}$ & High & $81-100$ \\
$\mathbf{2}$ & Sufficient & $61-80$ \\
$\mathbf{3}$ & Average & $41-60$ \\
$\mathbf{4}$ & Low & $21-40$ \\
$\mathbf{5}$ & Insufficient & $0-20$ \\
\hline
\end{tabular}

Thus, we calculated the average level of adherence according to the pharmacotherapy scheme for each patient $(n=55)$, by the proposed 5 categories. We established that 17 patients $(30.9 \%)$ have high level of adherence, 15 patients $(27.3 \%)-$ sufficient and only $6(10.9 \%)$ respondents - average level. However, $30.9 \%(14.5 \%+16.4 \%)$ of patients have low and insufficient level of adherence (Figure 2).

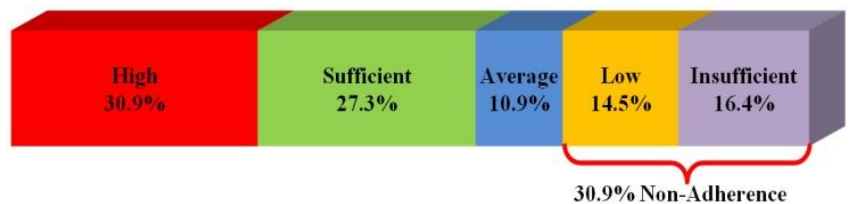

Fig. 2: Distribution of patients according to calculated the average level of adherence.

During the next stage of the study we conducted calculation of adherence level for each drug separately. In total, 55 patients were prescribed 132 drugs, 5 drugs out of total drugs were not taken by patients the at all due to their high cost. We found that patients had a high adherence level only in the application of $60(45.5 \%)$ drugs (Table 5). Subsequently, we singled out the top-
10 pharmacotherapy group of medicines, application of which is ranked as a high level of adherence (81-100\%) (Table 6).

Table 5: Distribution of analyzed drugs by the level of adherence in the context of 5 categories which we offered.

\begin{tabular}{ccc}
\hline $\begin{array}{c}\text { Medicines } \\
\text { Frequency }(\mathbf{n = 1 3 2})\end{array}$ & Percentage & $\begin{array}{c}\text { Gradation of adherence level } \\
\text { for each of the medicines }\end{array}$ \\
\hline 60 & 45.5 & High $(81-100 \%)$ \\
11 & 8.3 & Sufficient $(61-80 \%)$ \\
19 & 14.4 & Average $(41-60 \%)$ \\
23 & 17.4 & Low $(21-40 \%)$ \\
19 & 14.4 & Insufficient $(0-20 \%)$ \\
\hline
\end{tabular}

Table 6: Top-10 pharmacotherapy group of medicines, application of which is ranked as a high level of adherence (81-100\%).

\begin{tabular}{ll}
\hline Cod ATC & Pharmacotherapy group \\
\hline J01 & Antimicrobial drugs for systemic use \\
A10 & Antidiabetic drugs \\
G04 & Drugs for the treatment of urogenital organs \\
M01 & NSAIDs and anti-rheumatic drugs \\
B01 & Antithrombotic drugs \\
C01 & Cardiologycal drugs \\
L02 & Drugs used for hormonal therapy \\
H03 & Thyrotropic drugs \\
N06 & Psyhoanaleptics \\
R05 & Drugs used in cough and respiratory diseases \\
\hline
\end{tabular}

In order to confirm or refute our scientific hypotheses we conducted a statistical correlation and regression analysis to establish the presence or absence of links between the variables studied. The presence of a inversely proportional link between variables and its authenticity is confirmed in the following pairs of variables studied (Fig. 3-5). It was established that the level of adherence declines with the increase of number prescribed medicines $(\mathrm{r}=-0.33 ; \mathrm{R}=-0.35 ; \mathrm{p}<0.05)$ (Figure 3$)$.

Thus, according to the study the level of adherence decreases with the number of patient's diseases $(r=-0.27 ; R=$ $0.25 ; \mathrm{p}<0.05)$ (Figure 4).

In the latter, it was established that the level of adherence* $^{*}$ decreases with increasing cost of medicines** (Figure $5),(r=-0.17 ; R=-0.19 ; p<0.05)$. Thus, the results of the survey demonstrated that the high cost of medicines is one of the reasons for non-adherence. Currency rate of 1 USD as of Sep. 01.2015 constituted 21.81 UAH according to the National Bank of Ukraine (Official Website, 2015). The level of official average salary constituted 1378 UAH of then (The Law of Ukraine «On National Budget for 2015», 2015). In our opinion, this reason is a particular characteristic of the population of Ukraine, because most of the patients have low purchasing power to purchase drugs for their own pharmacotherapy. Our scientific hypothesis that the level of adherence increases in elderly patients in contrast to the young persons was not confirmed. Accordingly, the level of adherence does not depend on the age of the patient $(r=-0.10 ; R=-0.12$; $\mathrm{p}>0.05$ ) (Figure 6). The results of the our study revealed a number of typical national health factors that probably caused the nonadherence by analyzed patients, those mentioned factors were codified by us into 3 categories: 1) factors related to the patient $(59.7 \%) ; 2)$ factors related to pharmacotherapy $(26.9 \%)$; 3) socioeconomic factors $(13.4 \%)$ (Table 7$)$. 


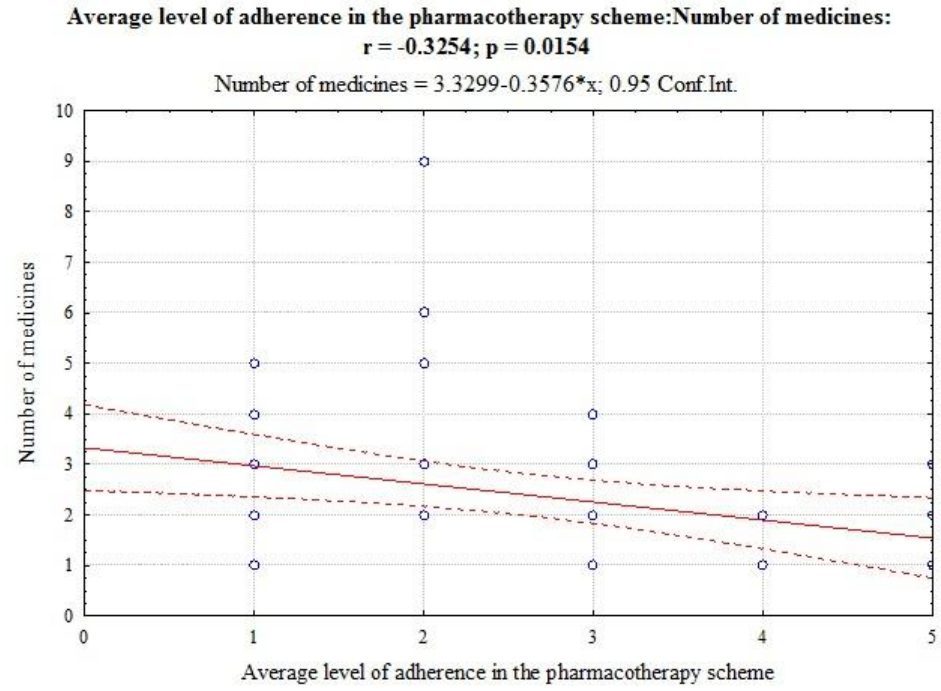

Fig. 3: Scatterplot of medicines number against average level of adherence in the pharmacotherapy scheme.

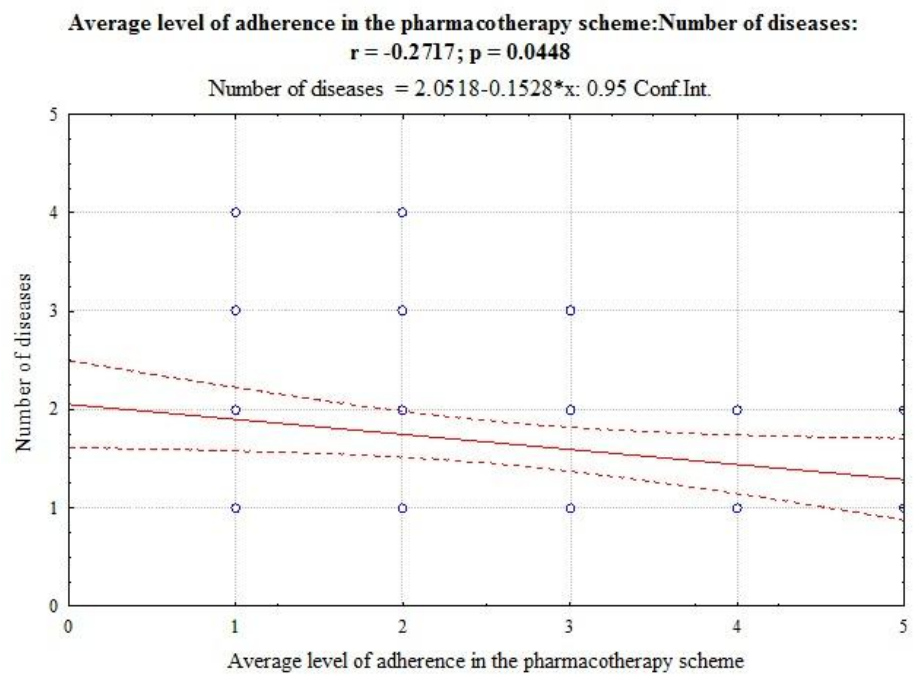

Fig. 4: Scatterplot of diseases number against average level of adherence in the pharmacotherapy scheme.

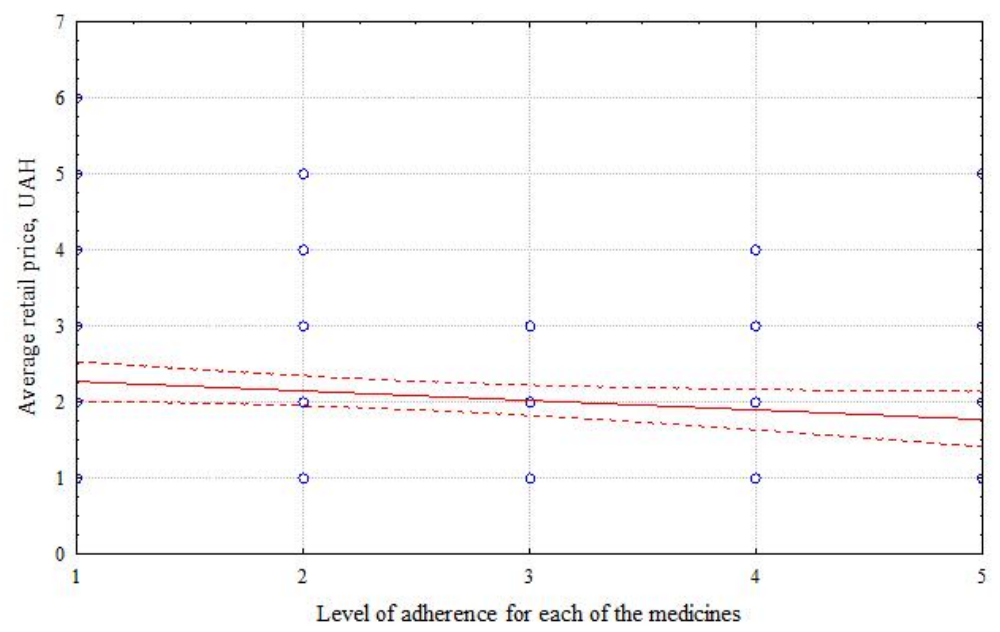

Fig. 5: Scatterplot of the medicines cost against the level of adherence by medicine.

*Level of adherence in this case was calculated for each drug separately $(\mathrm{n}=132)$. *** Cost of medicines, (UAH): 1 - very cheap $(0-50) ; 2-$ cheap $(51-150) ; 3-$ reasonably expensive (151-300); 4 - relatively expensive (301-500); 5 - expensive (501-1000); 6 - very expensive $(>1000)$ 


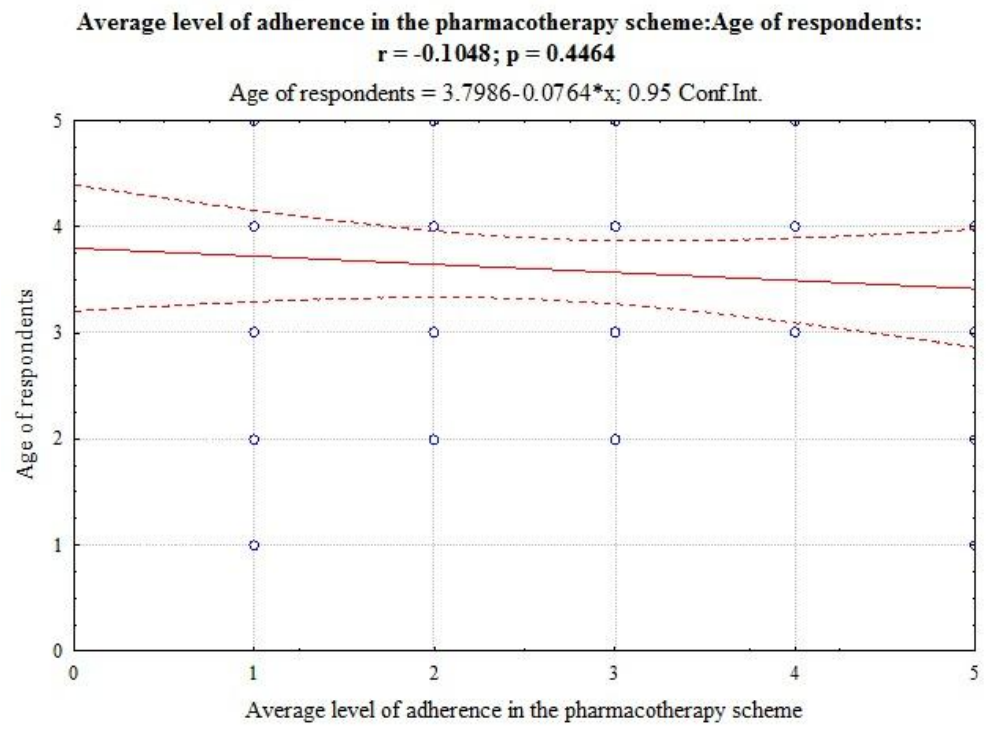

Fig. 6: Scatterplot of age of respondents against the average level of adherence in the pharmacotherapy scheme.

Table 7: The share of non-adherence factors identified with the analyzed patients.

\begin{tabular}{lcc}
\hline Factors & Frequency & Percentage \\
\hline Related to the patient & 24 & 20.3 \\
Patients don't feel the result of the treatment, find drugs ineffective & 23 & 19.3 \\
Bad memory (patients forgot to take medicines) & 22 & 18.5 \\
Change of feeling & 1 & 0.8 \\
Large size of the pills & 1 & 0.8 \\
Impact information from Internet, patient information leaflets & $\mathbf{7 1}$ \\
\hline Related with pharmacotherapy & $\mathbf{5 9 . 7}$ \\
\hline ADRs & 20 \\
Several drugs prescribed simultaneously & 12 & 16.8 \\
\hline Socio-economic factors & $\mathbf{3 2}$ & 10.1 \\
\hline High cost of drugs & & \\
Social problems (irregular working hours, loneliness) & 10 \\
Advice of relatives (friends) not to take some medications & 3 \\
\hline
\end{tabular}

Table 8: The problems of non-adherence to pharmacotherapy, identified with the analyzed patients.

\begin{tabular}{lcc}
\hline The problems of non-adherence & Frequency $(\mathbf{n = 1 3 7})$ & Percentage \\
\hline Missed drugs dosage & 55 & 40,1 \\
Insufficient duration of pharmacotherapy & 45 & 32,9 \\
Insufficient frequency of expected intake & 20 & 14,6 \\
"Drugs holidays" for 1 month & 8 & 5,8 \\
Never applied medicines & 5 & 3,7 \\
Drug dosage divided into half, $1 / 2$ & 4 & 2,9 \\
\hline
\end{tabular}

According to «face-to-face» interview of 55 respondents, we identified six major problems of non-adherence to prescribed pharmacotherapy by the doctor, which repeated 137 times (Table $8)$. On average per each patient there were $2.5 \pm 2.2$ problems accounted. It should be noted, that certain drugs were used according to doctor's prescription, and others - incorrectly, so sometimes there were a few problems per one person in scheme within one of pharmacotherapy. In particular, the patient, who was prescribed three drugs, took 2 of them with violation to compliance, and only one drug - correctly. We established that the most common problems were: missed drugs dosage (40.1\%), insufficient duration of pharmacotherapy (32.9\%) and frequency of expected intake (14.6\%) (Table 8). In addition, in 8 cases the patients arranged "drugs holidays" for themselves and 5 patients never used drugs.

\section{DISCUSSION}

Taking into account the current state of national health care system development and its insufficient development in terms 
of innovation and information technologies the only possible method in Ukraine today, to determine adherence could be carried out by means of subjective methods. Thus, one of these methods, chosen was "face to face" patient's interview conducted by phytotherapeutist in one of the pharmacies in Lviv. This method, in our opinion, has several advantages, including the possibility of direct contact with the patient and the possibility of detailed questions or clarifications. An additional factor of objectivity of respondents, in our opinion, was that the survey was not conducted directly by a physician, as patients usually overestimate their own discipline towards the use of medicines. During stage we have analyzed available modern subjective and objective methods of determining adherence of patients (Koncz, 2010).

In the world scientists most often use Morisky Medication Answers Scale (MMAS-8) (Wasilewski et al., 2014), which includes division of adherence into 3 categories: low adherence ( 0 to $<6)$; medium adherence ( 6 to $<8)$; high adherence (8). At the same time, this method is often used to determine the level of adherence for long-term therapies, in particular: hypertension, tuberculosis, diabetes mellitus etc. It should be noted, that the application of 42 drugs was indicated as $100 \%$ adherence, because these drugs were taken in hospital under the supervision of medical staff. However, in 2 cases exceeding of the duration of drugs use was found. In particular, the calcium-based drug was applied throughout the year instead of 45 days, therefore duration of pharmacotherapy has been exceeded by more than 8 times. Moreover, the patient took the calcium-based drug together with some milk which leads to insufficient drug absorption, and thus - decrease of pharmacotherapy efficiency. Special attention should be paid to the case where the prescription has been fully followed by the patient, but, it has been incorrectly prescribed by the doctor. Namely, the doctor prescribed antibiotic of the fluoroquinolone group for a 7 years old child, though according to the drug instruction for medical use, it is contraindicated to children under 18 . We consider that described cases can lead to adverse drug effects of medicines and complications of pharmacotherapy and therefore, these are the reasons of adherence absence.

WHO experts distinguish potential causes of nonadherence: 1) patient-related factors; 2) therapy-related factors; 3) condition-related factors patient's state influencing the adherence to pharmacotherapy, level of patient's disability, the rate of progression of the disease, depression, etc.); 4) social/economic factors; 5) health system/HCT-factors. Thus, the adherence is a multidimensional concept, which is determined by interaction of groups above 5 factors (Sabate, 2003). In our research revealed a number of typical national health factors that probably caused the non-adherence by analyzed patients: factors related to the patient; factors related to pharmacotherapy and socio-economic factors.

\section{Limitations}

The study had several limitations. The main of them is relatively modest size sample. Another drawback is that research was conducted only in one drugstore and in one town. Therefore the findings cannot be statistically generalized. Therefore, it is necessary to conduct more research in this area.

\section{CONCLUSIONS}

We consider that taking into account the current state of national health care system development and its insufficient development in terms of innovation and information technologies the only possible method in Ukraine today, to determine adherence could be carried out by means of subjective methods. In the highly developed countries contrary to Ukraine, most scientists use electronic monitoring, because this method meets the requirements of objectivity, reliability and reproducibility.

The results of the research found that level of adherence declines with the increase of number prescribed drugs, diseases of the patient and the cost of medicines. However, the level of adherence does not depend on the age of the patient. The optimal way to increase the level of adherence with the patients to pharmacotherapy is the integration of subjective and objective methods of adherence evaluation in the current health care system of Ukraine, in particular, through implementation of DRP methodology and professional activity of a clinical pharmacist.

\section{Financial support and sponsorship: Nil.}

Conflict of Interests: There are no conflicts of interest.

\section{REFERENCES}

Delamater AM. Improving patient adherence. Clin. Diabetes, 2006;24(2):71-77.

Fischer MA, Stedman MR, Lii J, Vogeli C, Shrank WH, Brookhart MA, Weissman JS."Primary Medication Non-Adherence: Analysis of 195,930 Electronic Prescriptions”. Journal of General Internal Medicine, 2010; 25(4): 284-290.

Hema K, Padmalatha P. Adherence to medication among Hypertensive patients attending a tertiary care hospital in Guntur, Andhra Pradesh. Indian Journal of Basic and Applied Medical Research, 2014; 4(1):451-456.

Improving Prescription Medicine Adherence is Key to Better Health Care. Taking Medicines as Prescribed Can Lower Costs and Improve Health Outcomes. PhRMA, 2011.[ONLINE] Available at: Available at: http://docplayer.net/2753720-Improving-prescriptionmedicineadherence-is-key-to-better-health-care.html

Koncz T. Clinical and pharmacoeconomic impact of patient medication adherence.2010; 106. [ONLINE] Available at: http://phd.semmelweis.hu/mwp/phd_live/vedes/export/koncztamas.d.pdf

Nagarkar AM, Swapnil A Gadhave, Ishor Sharma, AnkitaChoure, Donald Morisky. Factors influencing medication adherence among hypertensive patients in a tertiary care hospital. National Journal of Community Medicine, 2013; 4(4): 559-563.

National Bank of Ukraine. Official Website as of Sep. 01.2015, [ONLINE] Available

Nichols G, Poirier S. Optimizing adherence to pharmaceutical care plans. J Am Pharm Assoc, 2000; 40(4): 475-485.

Osterberg L, Blaschke T. Adherence to medication. N Engl J Med. 2005; 353(5):487-497. 
Sabate E. World Health Organization (WHO). 2003. Adherence To Long-Term Therapies: Evidence For Action. Switzerland. [ONLINE] Available at: http://whqlibdoc.who.int/publications/2003/9241545992.pdf

The Average Retail Price of Medicines in Ukraine http://compendium.com.ua/prices.

The Law of Ukraine «On National Budget for 2015» on 28.12.2014 № 80-VIII. (Edition on 29.12.2015).[ONLINE] Available at: http://zakon5.rada.gov.ua/laws/show/80-19.

The State drugs list of Ukraine. 2015.[ONLINE] Available at: http://www.drlz.kiev.ua.

Van den Bemt BJ, Zwikker HE, van den Ende CH. Medication adherence in patients with rheumatoid arthritis: a critical appraisal of the existing literature. Expert Rev ClinImmunol., 2012; 8(4):337-351.

Wasilewski JG,Milaniak I, Janik Ł, Sadowski J, Przybyłowski P. Adherence to antihypertensive therapy among heart transplant recipients. KardiochirurgiaiTorakochirurgiaPolska,2014;11 (3):343-348.

Zwikker HE, Sandra van Dulmen, Alfons A den Broeder, Bart J van den Bemt, Cornelia $\mathrm{H}$ van den Ende. Perceived need to take medication is associated with medication non-adherence in patients with rheumatoid arthritis. Patient Preference and Adherence, 2014; 8: 16351645.

\section{How to cite this article:}

Ryvak T, Makukh K, Zimenkovsky A. Assessment of Drug Adherence Level According to the Patients' Opinion: Results of Research in Lviv of Ukraine. J App Pharm Sci, 2017; 7 (04): 149-

156. 